\title{
PROCESSOS DE ESPOLIAÇÕES NO BRASIL ATUAL: OFENSIVAS DO AGRONEGÓCIO SOBRE OS DIREITOS AMBIENTAIS E TERRITORIAIS
}

\author{
PROCESOS DE DESPOJO EN BRASIL HOY: OFENSIVAS DEL AGRONEGOCIO SOBRE \\ DERECHOS AMBIENTALES Y TERRITORIALES
}

Daniel Macedo Lopes Vasques Monteiro ${ }^{\mathrm{A}}$

\author{
${ }^{\text {A }}$ Universidade Federal do Rio de Janeiro (UFRJ), Rio de Janeiro, RJ, Brasil
}

Recebido em: 04/11/2021 | 04/01/2022～DOI: $10.12957 /$ tamoios.2022.63317

Correspondência para: Daniel Macedo Lopes Vasques Monteiro (danielmlvm@yahoo.com.br)

\begin{abstract}
Resumo
Nos últimos anos a crise ambiental vem se intensificando no mundo e, mais fortemente, no Brasil. O contexto político atual brasileiro favorece o avanço das áreas agricultáveis voltadas para a exportação de commodities. Nesse sentido, o seguinte artigo tem como objetivo compreender o avanço das ofensivas que favorecem o agronegócio em contraposição às questões ambientais e aos territórios de grupos que não correspondem a racionalidade capitalista nessas áreas de espoliação. No trabalho buscar-se-á compreender os processos de espoliação dos setores do agronegócio que envolvem etapas como o desmatamento, a grilagem de terra, o uso exacerbado de agrotóxicos e os projetos de lei que tramitam nas esferas institucionais. Acrescenta-se que a análise foi feita de acordo com a perspectiva analítica anti-colonial, buscando compreender o território de acordo com os sujeitos que nele vivem e lutam contra o avanço da fronteira agrícola capitalista.
\end{abstract}

Palavras-chave: Questão ambiental; agronegócio; acumulação por espoliação; fronteira agrícola; geografia anti-colonial

\section{Resumen}

En los últimos años, la crisis ambiental se ha intensificado en el mundo y, con más fuerza, en Brasil. El actual contexto político brasileño favorece el avance de las áreas agrícolas destinadas a la exportación de commodities. En este sentido, el siguiente artículo tiene como objetivo comprender el avance de ofensivas que favorecen lo agronegocio frente a las cuestiones ambientales y los territorios de grupos que no corresponden a la racionalidad capitalista en estas áreas de despojo. El trabajo buscará comprender los procesos de despojo de los sectores del agronegocio que involucran etapas como la deforestación, la usurpación de tierras, el uso exacerbado de plaguicidas y las facturas que se están tramitando en los ámbitos institucionales. Se agrega que el análisis se realizó desde la perspectiva analítica anticolonial, buscando entender el territorio según los sujetos que lo habitan y luchan contra el avance de la frontera agrícola capitalista.

Palabras clave: Problema medioambiental; agronegocio; acumulación por despojo; frontera agrícola; geografía anticolonial

\section{INTRODUÇÃO}

A história do Brasil é ligada a um processo de expansão dos cultivos voltados à exportação de sua produção. No atual contexto, a lógica de certa forma ainda permanece, sendo ampliadas as estratégias empresariais de exploração dos espaços ainda não conectados às redes globais de produção e consumo. As fronteiras agrárias do capital avançam em 
espaços que correspondem a outras lógicas de organização. A chegada dos agentes capitalistas perpassa pela lógica de acumulação e reprodução do capital.

Desta forma, há um grande embate quando a fronteira agrária capitalista chega em porções do território nacional brasileiro. Este artigo tem como objetivo compreender o avanço das ofensivas que favorecem o agronegócio, em contraposição às questões ambientais e aos territórios de grupos que não correspondem à racionalidade capitalista nessas áreas de espoliação. Esta análise justifica-se ao fato de, nos últimos anos, haver um crescente número de desmatamento, de grilagem, de usos de agrotóxicos e de leis que corroboram com essas práticas.

O trabalho divide-se em 4 partes. Na primeira parte, com a leitura de Harvey (2005), busca-se compreender os novos mecanismos encontrados pelo capitalismo que corroboram para a acumulação primitiva nos tempos atuais. Na segunda parte destaca-se a necessidade de compreendermos uma leitura do território que dialogue com os movimentos sociais, com os povos tradicionais e com os valores trazidos por suas identidades (MALHEIRO; PORTO-GONÇALVES; MICHELOTTI, 2021 e HAESBART, 2021). Na terceira parte, dados secundários foram ressaltados com a finalidade de exemplificar as ofensivas sobre a questão ambiental, assinalando a grave situação dos desmatamentos, dos processos de grilagem, dos usos exacerbados de agrotóxicos e de projetos de leis que tramitam na esfera federal com a intenção de tornar legal tais processos de destruição. Por fim, na quarta parte, uma análise de conclusão que questiona o papel e o discurso do agronegócio, ressaltando a importância e a valorização de compreendermos um mundo para além dos valores do mercado.

O que será valorizado neste trabalho não será o território que prioriza as propriedades jurídico-políticas, como fazem as matrizes europeias, principalmente as anglo-saxônicas. Mas o território em seu uso como instrumento de luta e de transformação social (Haesbaert, p.161, 2021). Ou seja, um território que parte da esfera do vivido, das suas práticas e dos seus usos.

\section{ACUMULAÇÃO POR ESPOLIAÇÃO E O PAPEL DO ESTADO}

Para iniciar o debate, faz-se necessário ressaltar que as relações capitalistas com os modos de produção não-capitalistas perpassam por ações políticas de cunho colonizador. Dentre as características descritas por Harvey (2005), podemos destacar algumas que ajudam a compreender a situação dos espaços pretéritos e atuais da fronteira agrícola no Brasil.

A mercadificação da natureza, segundo o autor, ocorre através da destruição dos recursos naturais e da degradação dos habitats, na supressão/eliminação de formas alternativas de produção de consumo, na supressão/eliminação dos direitos dos camponeses a terras comuns, na monetização da terra, na mercadificação da força de trabalho, nos processos coloniais/neocoloniais/imperiais de apropriação dos bens naturais, entre outros. Harvey 
(2005) também afirma que a acumulação primitiva envolve a apropriação e a cooptação de realizações culturais e sociais preexistentes, gerando confronto e repressões.

É nesse sentido que Harvey (2005) utiliza o termo acumulação por espoliação, substituindo a nomeação do "primitivo", já que é uma acumulação que ocorre no sentido de ser um processo. Harvey traz para o debate que o processo de acumulação, que transborda a relação da acumulação por mais-valia, não ocorre somente na etapa inicial do capitalismo, como assegura Marx. Harvey afirma que as características da acumulação primitiva ocorrem em um processo contínuo, ele se repete em ciclos de acumulação por espoliação, "tem caráter de estratégias permanentes, e não circunstanciais no capitalismo (...), a usurpação e a apropriação da propriedade social por uma minoria têm características contínuas ao longo da história desse sistema social" (BRANDÃO, p.46, 2010). Essa atualização do conceito feito por Harvey torna-se pertinente para analisar o avanço da fronteira agrícola e a racionalidade da lógica de degradação socioambiental que ocorre no Brasil.

O Estado tem um papel nesse processo; Marx nos revela que os diferentes métodos de acumulação primitiva utilizam o poder estatal. Assim, Harvey acrescenta que, além do monopólio da violência, o Estado é quem determina a definição de legalidade. Desse modo, o processo de transição dos espaços não-capitalistas para o capitalismo e as formas de acumulação por espoliação dependem do Estado. O Estado mantém as lógicas territoriais e capitalistas para cumprir com o seu papel desenvolvimentista. De acordo com Brandão (2010),

os Estados são dominados pelos grandes interesses do poder financeiro e pela força de estruturas empresariais de porte; as propriedades e as fortunas mercantis, fundiárias e imobiliárias, cada vez mais financeirizadas, continuam a ter papel central no funcionamento do sistema capitalista tanto em termos globais como em nacionais $(\mathrm{p} .42,2010)$.

As ideias desenvolvimentistas pairam sobre a história do Brasil, e as investidas do Estado para alcançar o desenvolvimento são contínuas. A busca por um desenvolvimento econômico atrelado ao progresso faz parte dos momentos políticos e desenham as ações dos agentes sociais no território do país, seja através dos agentes que idealizam e constroem subsídios para o fortalecimento de políticas desenvolvimentistas ou daqueles que estão "no meio" desses traçados. Os que não fizeram parte da construção desses ideais também são afetados pelas políticas desenvolvimentistas que ocorreram, além de serem considerados, na maior parte das vezes, entraves para a execução de tais políticas.

OS "CORTES DE NAVALHAS" E OS "TERRITÓRIOS SACRIFICADOS": UM OLHAR ANTICOLONIAL SOBRE A RACIONALIDADE EXPANSIONISTA DO AGRONEGÓCIO 
A implementação das redes de infraestrutura planejadas e construídas no território brasileiro se impuseram/impõe sobre os territórios dos que ali já viviam. Atualmente isso ocorre com mais intensidade nas áreas de expansão do agronegócio na Amazônia e nos Cerrados do Centro-Oeste e do MATOPIBA ${ }^{1}$, principalmente no que tange às rotas logísticas de escoamento da produção de commodities. Desde as linhas telegráficas de Rondon, até as estradas, ferrovias e hidrovias, eixos são traçados no território nacional, obedecendo a racionalidade inserida em uma lógica expansionista.

Malheiro, Porto-Gonçalves e Michelotti (2021) trazem, no livro "Horizontes Amazônicos: para repensar o Brasil e o mundo", uma boa definição para o que chamamos de redes de expansão. Anacleta Pires, liderança quilombola do Maranhão, que teve sua comunidade perpassada pelos trilhos da Estrada de Ferro Carajás, define como "cortes de navalha", para ela não são eixos de expansão ou corredores de exportação, mas sim "navalha que corta tudo". Assim, podemos compreender que as "redes de infraestrutura para o desenvolvimento do país", traçada pelo Estado e pelas empresas públicas ou privadas, são navalhas que cortam o território de quem ali já vivia. A visão, o olhar e o modo de se compreender o espaço, precisa também ser descolonizado por nós pesquisadores.

Esses "cortes de navalha" obedecem a uma racionalidade lógica capitalista, que vê a natureza como obstáculo ou como mercadoria. A lógica de expansão dessa racionalidade é autoritária, há sempre a criminalização e judicialização dos que dela são críticos e daqueles que se colocam contra. Além disso, são desde o princípio militarizadas e milicializadas ${ }^{2}$ (MALHEIRO, 2021).

Trataremos esses espaços espoliados como "territórios de sacrifício" (HAESBAERT, 2021), ou seja, territórios "a serem "sacrificados" em prol de um pretenso desenvolvimento",

em função da acumulação ilimitada e da exploração predatória dos recursos. Trata-se de um "modo particular de acumulação" (Terán, 2016) ou um modelo de produção fundado na extração em massa/superexploração de recursos naturais não processados (Gudynas, 2009) (HAESBAERT, p.60, 2021).

Esses territórios vistos como obstáculos pela racionalidade expansionista, tornam-se espaços onde o modelo econômico extrativista ou neoextrativista tenta se impor. $\mathrm{O}$ agronegócio é um exemplo de imposição. Podemos ler esse desenvolvimentismo brasileiro nas últimas décadas como um modelo neoextrativista, voltado para as ações do capital. Não só no Brasil, mas em toda América Latina, um neoextrativismo, aliado ao capitalismo neoliberal (HAESBART, 2021), com o aval do Estado, inclusive como projeto político dos governos progressistas do continente

adquire novas dimensões, não só objetivas - pela quantidade e pela escala dos projetos, pelos diferentes tipos de atividades, pelos atores nacionais e internacionais envolvidos -, mas também subjetivas, a partir do surgimento de grandes resistências sociais, que questionaram o avanço vertiginoso da fronteira de commodities e, diante 
do espólio, foram elaboradas outras linguagens e narrativas em defesa de outros valores -a terra, o território, os bens comuns, a natureza etc. (p. 18). (SVAMPA, p.18, 2019).

Por isso, a necessidade e a importância de se compreender o território com base em um debate anticolonial. Dessa forma, Haesbaert (2021) reforça a importância do debate de "território usado" do Milton Santos, para além do "simples valor de uso" e das ações dos homens, mas também um território que perpassa as noções do simbólico, do vivido, do emocional, do espiritual.

\section{O DIREITO CONSTITUCIONAL SOBRE O MEIO AMBIENTE ECOLOGICAMENTE EQUILIBRADO E AS PRINCIPAIS OFENSIVAS NO PERÍODO ATUAL}

A defesa e a proteção do meio ambiente são respaldadas como direito garantido na Constituição de 1988 no Brasil. No entanto, o debate em relação às questões ambientais não surge somente nesse momento no país. Desde o período colonial, por exemplo, encontra-se algumas leis que se configuravam visando o controle do uso dos recursos hídricos, principalmente quando voltados à mineração em Minas Gerais (FONSECA; PRADO FILHO, 2006). No entanto, os registros oficiais que datam da república, no que concerne à política ambiental brasileira, têm marcos importantes; destacamos aqui o Código das Águas em 1934, o Código Florestal Brasileiro em 1965, a Conferência de Estocolmo em 1972³ e, em 1981, a Política Nacional do Meio Ambiente.

Esse é o contexto prévio das legislações ambientais que tramitaram no Brasil antes da Constituição de 1988. Nela destaca-se o artigo 225, que "garante a todos o direito ao meio ambiente ecologicamente equilibrado, bem de uso comum do povo e essencial à sadia qualidade de vida, impondo-se ao poder público e à coletividade o dever de defendê-lo e preservá-lo para as presentes e futuras gerações". Vale apontar, a criação do Instituto Brasileiro do Meio Ambiente e dos Recursos Naturais Renováveis (IBAMA), um ano depois, em 1989.

Assim, é de acordo com o direito garantido e pautado na Constituição que faremos a análise da compreensão do momento atual político do país. A propagação da pandemia da Covid-19 no mundo, se alastrou no período 2020/2021 . O mundo todo voltou seus olhares para a doença, para as formas de prevenção, para os meios de propagação, para os prejuízos econômicos causados e para a dor das mortes dos entes próximos, ao mesmo tempo, em que o Brasil é governado por um executivo negacionista, no que tange aos debates científicos ${ }^{5}$.

Desde o princípio de sua gestão evidenciou-se que as decisões a seguir não buscavam sustentação nos aparatos científicos, seja a sua negação por desconhecimento, ou por 
desqualificação ideológica. Um fato que marcou, logo no início de seu mandato, foi a demissão de Ricardo Galvão, em agosto de 2019, diretor do Instituto Nacional de Pesquisas Espaciais (INPE), após o ataque do presidente em que afirmava que o instituto se comportava de forma antagônica aos interesses do país. Dessa forma, colocou em dúvida e depreciou os dados sobre o desmatamento divulgados naquele momento. É importante destacar que, apesar do INPE ser um órgão incluso na pasta do Ministério da Ciência e Tecnologia, os embates ocorriam em desavenças com o Ministro Ricardo Sales, até então, da pasta de Meio Ambiente. Demonstrava, desde já, no ano inicial de seu mandato, uma prévia de como o governo trataria a ciência e a questão ambiental.

Retornando ao contexto da pandemia, no dia 22 de maio de 2020 o país assistiu atônito à reunião do presidente Bolsonaro com seus ministros. Dentre as atrocidades esbravejadas pelos participantes, destacamos aqui o ator que nos interessa, Ricardo Sales. O ministro enfatizou que seria interessante aproveitar o foco na Covid-19 para "ir passando a boiada e mudando todo o regramento e simplificando normas". Assim sendo, neste item abordaremos, brevemente, os principais assuntos que dizem a respeito à "boiada" de Salles e ao agronegócio.

\title{
A fronteira agrícola no rastro do desmatamento
}

O agronegócio, a cada ano que passa, tenta desassociar sua imagem dos índices que o conectam com os elementos do atraso, ainda presente na estrutura fundiária brasileira. Exisem termos que eles tentam se desvincular, ou ressignificar, como: "queimadas", "trabalho escravo", "desmatamento", "latifúndios", "agrotóxicos", "monocultura” etc. O setor busca mudar sua imagem, com aparatos discursivos e midiáticos.

No entanto, o movimento da fronteira demonstra que o agronegócio está no rastro do desmatamento. Como colocado por Bernardes,

\begin{abstract}
A pecuária bovina frequentemente é responsável pela inauguração de fronteiras: num primeiro momento ocorre a extração de madeira, em seguida vem o desmatamento e, após este, e por vezes, queimadas, é realizado o plantio de pastagens. O ônus ambiental decorrente desse processo de expansão é muito elevado e se expressa na deterioração do meio físico-biótico em função do elevado nível de desmatamento e na ruptura étnico-cultural, resultando na perda de identidade por parte de segmentos nativos longamente adaptados aos ecossistemas ali dominantes. (BERNARDES, 2021).
\end{abstract}

Dados atuais do Relatório Anual do Desmatamento no Brasil (2020), do MapBiomas, revelam números assustadores da questão ambiental brasileira atual. Destaco que, de antemão, o relatório faz uma comparação com o ano anterior (2019); a priori deixo ressalva ao fato do relatório mencionar que apenas $0,9 \%$ das propriedades rurais desmataram no Brasil entre 2019 e 2020. Porém, vale destacar o fato que, diversas áreas já foram desmatadas 
anteriormente, no movimento da fronteira; se analisarmos no período de 10 ou 20 anos até agora, perceberemos que o agronegócio foi se instalando nas áreas que a princípio eram florestadas.

Após essa ressalva, destacamos alguns dados extremamente importantes do relatório que nos ajudarão a mapear as características do desmatamento no Brasil no ano de 2020. Em média, no país, foram detectados 203 alertas de desmatamentos por dia, o que demonstra a magnitude das ações e a necessidade de alinhar as políticas públicas às geotecnologias de análise de imagem por satélites.

$\mathrm{O}$ número de alertas cresceu em praticamente todos os biomas, com destaque para a concentração na Amazônia, e a crescente variação no Pantanal, como observado em 2020 com as intensas queimadas e a conivência do setor federal. Seis estados correspondem a $76 \%$ dos desmatamentos no Brasil, são eles: Pará, Mato Grosso, Maranhão, Amazonas, Rondônia e Bahia.

Os municípios brasileiros que obtiveram alertas de desmatamento detectado totalizaram 2.577, ou seja $46 \%$ dos municípios do país, correspondendo a $100 \%$ dos municípios dos estados do Amazonas, Acre, Amapá e Rondônia. Os 10 municípios que mais desmataram respondem por $23 \%$ do desmatamento em todo país, sendo seis localizados no Pará, dois no Amazonas, um em Rondônia e um no Maranhão ${ }^{6}$.

O maior desmatamento identificado foi em Altamira, correspondendo a 6.469 ha. A área corresponde a uma gleba pública federal, não tem CAR (Cadastro Ambiental Rural), não se sobrepõe a Terra Indígena, nem assentamento, e nem Unidade de Conservação. Tudo indica ser uma área de terra grilada ${ }^{7}$. Este município localiza-se nas margens da BR-163, forte "corte de navalha" (eixo de expansão) do desmatamento, da grilagem, das áreas para pasto e, consequentemente, das áreas agricultáveis para os grãos. A fronteira da expansão agrícola no estado do Pará segue o fluxo de forma semelhante e devastadora à que ocorreu no estado de Mato Grosso.

O desmatamento mais rápido, em 2020, foi no município de Baixa Grande do Ribeiro, no Piauí, onde foram desmatados 1.428 ha em 15 dias, ou seja, 89 ha por dia. É uma área de expansão da produção de grãos no MATOPIBA, próxima à cidade de Bom Jesus, centro pujante do agronegócio no estado. De acordo com dados da Produção Agrícola Municipal do IBGE, em apenas 5 anos, entre 2010 e 2015, a área plantada de soja no município aumentou em $18 \%$.

Outros dados do Relatório Anual do Desmatamento no Brasil (2020), do MapBiomas, revelam a rapidez com que ocorre o desmatamento. Somente no dia 31 de julho de 2020, o país registrou a marca de $575 \mathrm{~m}^{2}$ por segundo de área desmatada, equivalente a aproximadamente mais de 2 milhões de árvores cortadas em um único dia. De acordo com as estimativas do relatório, em 2020 o Brasil perdeu 24 árvores por segundo.

No que tange à totalidade do desmatamento, 7\% ocorreu em áreas indígenas, $\mathrm{o}$ número total cresceu 31\% em relação a 2019. Das 573 Terras Indígenas no Brasil, 297 
sofreram desmatamento, mais da metade, correspondendo a 51,8\%, o que demonstra a pressão sobre os territórios indígenas já demarcados ${ }^{8}$. Evidencia-se, também, que $14 \%$ da área desmatada no país ocorreu em Unidades de Conservação (estadual e federal), crescendo 5\% em relação a 2019. No tópico a seguir, analisaremos a causa da magnitude desse aumento nas terras públicas.

\section{A fronteira agrícola no rastro da grilagem}

O processo de desmatamento está diretamente ligado à grilagem de terras. Para grilar uma terra é necessário que, num primeiro momento, seja retirada a vegetação. Isso já consolida na ordem local que aquela terra "tem dono". "Dono é quem desmata": a frase foi proferida por um grileiro no estado do Pará, resumindo a realidade dessas áreas de fronteira no Brasil. Na lógica regional e no jogo de poder local, a regra é com base nessa máxima (TORRES, DOBLAS \&ALARCON, 2017). Após o desmatamento, num segundo momento, há a atuação junto aos cartórios para que haja o registro, feito de forma ilegal, dessas terras.

A grilagem é o exemplo clássico de acumulação por espoliação no Brasil, onde os instrumentos ainda arcaicos de produção de capital abrem espaços para a inserção de territórios no sistema-mundo capitalista/competitivo. Os mecanismos de burla, a psicosfera ${ }^{10}$ criada no local e, posteriormente, a legalização via aparato do Estado, caracterizam o espólio de áreas não-capitalistas, transformando-as em territórios calcados numa lógica produtivista.

$\mathrm{O}$ processo de grilagem de terra demonstra que o desmatamento não tem como objetivo máximo a extração da madeira e a comercialização ilegal. O processo nessas fronteiras está imbuído de uma lógica rentista e especulativa da terra. Áreas públicas protegidas, como Terras Indígenas e/ou Unidades de Conservação, por mais que sejam também atacadas, até então não eram de fato objetivo maior da grilagem. Até porque essas terras não poderiam ser transferidas ao patrimônio privado. A lógica do grileiro é transformar a terra em sua propriedade privada.

No entanto, os números recentes de aumento de pressão em cima de Unidades de Conservação e de Terras Indígenas podem ser ligados à hipótese de declarações proferidas pelo presidente da república e/ou por projetos de lei que tramitam e buscam permitir a posse dessas áreas protegidas. Em muitos casos, há a antecipação, uma aposta, de alguns grileiros, mais descapitalizados, em se apropriarem das terras públicas. Um exemplo foi a operação do IBAMA na Terra Indígena Araweté, em São Felix do Xingu, em abril de 2020. No momento da retirada dos invasores, o vereador local, Silvio Alves Coelho (PSC), argumenta "O próprio presidente vem sempre falando que vai diminuir o tamanho das áreas, que existe uma demanda para diminuir, que existe igualmente garimpo dentro dessas áreas, que existe uma possibilidade de legalizar parte dessas áreas. E todo mundo trabalha na esperança, esse povo aí"ll. 
De acordo com o Dossiê "Agro é Fogo", as imagens de satélite ainda não são capazes de identificar todas as áreas de fato desmatadas. Existem os casos daquele que não têm como objetivo direto o monocultivo ou a criação de gado extensiva, e realizam remoção somente do extrato inferior da floresta

\begin{abstract}
Nesses casos, são abertos ramais, cortadas árvores de valor comercial e abertos pátios pequenos de operação (chamados de esplanadas). Ainda que a floresta seja bastante degradada nesses processos, a alteração na cobertura do solo não é possível de ser registrada pelo sistema de monitoramento do desmatamento. (AGUIAR, TORRES, 2020, online)
\end{abstract}

Quando ocorre esse procedimento, é comum a derrubada, o saque e a comercialização de madeiras com a utilização da força de trabalho escravo. A atividade, por se configurar como ilegal e criminosa, é comandada por grupos que aterrorizam as comunidades locais, os que "vivem dentro das unidades de conservação, assentamentos de reforma agrária e terras indígenas" (AGUIAR, TORRES, 2020, online).

O relatório nos mostra ainda que o valor da terra, no Oeste do Pará, em 2017, em uma área desmatada, pode chegar a um preço 20 vezes maior do que uma área florestada. Destaca-se a proporcionalidade da quantidade de terras griladas após o anúncio do asfaltamento da BR-163. Assim, os "cortes de navalha" nos territórios vão deixando marcas que se alastram e não são cicatrizadas.

Os grileiros agem de diversas formas, seja na autodeclaração feita no CAR, ou seja até mesmo no auto de infração emitido pelo IBAMA. No relatório, os autores citam, que é comum o sujeito notificar ao IBAMA o seu próprio desmatamento ilegal. Dessa forma, o documento emitido pelo órgão comprova em nome do grileiro a posse da terra. A terra como posse produtiva redime aquele que desmatou de ser punido, anistiando-o do crime de grilagem. Dessa forma, o processo de desmatamento, grilagem e chegada da fronteira agrícola torna-se praticamente irreversível nos moldes das políticas atuais.

\title{
Agrotóxicos e o uso excessivo de venenos pelo agronegócio
}

$\mathrm{O}$ uso de agrotóxicos pelo agronegócio configura, hoje em dia, junto com o desmatamento, o principal dano ambiental provocado pelo setor. No que tange ao desmatamento, as ações do agronegócio são muitas vezes camufladas e surgem a posteriori dos fatos realizados. A justificativa do setor é que quem desmata são os madeireiros ou então há uma separação, apontando os crimes apenas para o ramo da pecuária. No entanto, o movimento da fronteira, como vimos, é desconsiderado por eles e as áreas desmatadas hoje serão ocupadas por grãos para suprir o mercado internacional de commodities no futuro.

Não obstante, as ações e os usos dos agrotóxicos são diretamente ligados ao setor, e impossível de serem camufladas. Neste caso, há dois destinos diretos na aplicação dos 
venenos, a saúde humana e a contaminação ambiental. Podemos alinhar o assunto à saúde, no que se refere a questão da alimentação do consumidor, mas também à saúde do trabalhador rural.

A aplicação dos venenos na plantação decorre da inovação tecnológica para a agricultura, pecuária e silvicultura. A lógica da eficiência (BERNARDES; SANTOS; NASCIMENTO, 2021), corrobora para o maior nível de aplicação nas lavouras, pastagens ou florestas replantadas para a indústria, sendo as etapas agrícolas cada vez mais necessitadas dos agrotóxicos. Servem tanto para eliminar insetos indesejáveis, como plantas que são concebidas como "pragas". No Brasil, conforme há a expansão na produção de commodities, ocorre também o aumento do uso de agrotóxicos.

O mercado mundial de agrotóxicos entre 2002 e 2012 cresceu 93\%, sendo que no Brasil esse aumento foi de 190\% (ANVISA apud ABRASCO, 2015). Destaca-se que em 2008 o Brasil tornou-se liderança como o maior mercado consumidor de agrotóxico do mundo, tendo o estado de Mato Grosso como destaque nacional.

De acordo com o Dossiê da ABRASCO (2015), um terço do que consumimos diariamente está contaminado com agrotóxicos. A pesquisa citada por eles, do Programa de Análise de Resíduos de Agrotóxicos em Alimentos (PARA) da Agência Nacional de Vigilância Sanitária (ANVISA, 2011), indica que dentre as amostras analisadas, 63\% apresentaram contaminação por agrotóxicos, sendo que $29 \%$ não autorizados na época ${ }^{12}$.

No entanto, os casos mais graves de intoxicação ocorrem com a população rural, principalmente aqueles trabalhadores que aplicam diretamente os venenos. A intoxicação pode ocorrer por inalação, por contato na pele ou por ingestão, ocasionando diversos sintomas ${ }^{13}$.

No meio ambiente os danos são causados na contaminação dos lençóis freáticos, dos rios, dos poços, da água da chuva, da terra, do ar, da fauna e da flora. Em diversas regiões do Brasil são encontrados indícios de contaminação, principalmente aquelas ligadas aos modos de produção do agronegócio. A pesquisa intitulada "Estudo epidemiológico da população da região do Baixo Jaguaribe exposta à contaminação ambiental em área de uso de agrotóxicos" revela a contaminação da água para consumo humano que abastece os munícipios de Limoeiro do Norte e Quixeré no Ceará. Foi encontrado agrotóxico em todas as amostras analisadas, desde o centro de abastecimento, até as torneiras de algumas casas. Destaca-se que os dois municípios fazem parte da região que concentra uma produção de frutas em larga escala, tanto para o mercado interno como para o externo.

O Dossiê da Abrasco ainda nos traz o exemplo, no ano de 2006, no município de Lucas do Rio Verde, onde a pulverização da soja transgênica por paraquat, próximo à cidade, ocasionou "a "queima" de 180 canteiros de plantas medicinais no centro da cidade, e de hortaliças em 65 chácaras” (ABRASCO, 2015, p. 71), desencadeando um surto de intoxicação aguda. 
No mesmo município de Mato Grosso foi realizada uma pesquisa para analisar o leite materno de 62 mães que estavam amamentando, entre 2 a 8 semanas após o parto. Em todas as amostras foram encontradas pelo menos um tipo de agrotóxicos. Os pesquisadores apontam que isso pode ter ocorrido devido ao fato da "exposição ocupacional, ambiental e alimentar do processo produtivo da agricultura que expôs a população a 136 litros de agrotóxicos por habitante na safra agrícola de 2010" (ABRASCO, 2015, p. 73).

Os estudos mostram também níveis excessivos de agrotóxicos localizados em mananciais hídricos, sendo encontrados em diversas regiões do Brasil, ligadas a vários tipos de cultivo. O estudo de Silva et all (2009), sobre o cultivo de arroz irrigado em 7 regiões do Sul do país, na safra 2007-2008, em 3 momentos, antes do plantio, durante o plantio e depois da colheita na drenagem da água, revela que foram encontrados agrotóxicos em todas as etapas e em todas as áreas coletadas, sendo a região da Lagoa dos Patos no Rio Grande do Sul a que mais concentrou número de agrotóxicos, já que 8 agrotóxicos dos 9 estudados, foram ali encontrados. Outras pesquisas apontam resultados semelhantes em diversas regiões do Brasil: Soares at all (2012) mostra contaminação em águas superficiais no município de Manhuaçu em Minas Gerais, na área de produção do café. Dores; Calheiros (2008) e Miranda et al. (2008) na contaminação dos afluentes do Rio Paraguai que afetam a planície pantaneira. Augusto (2010) na fruticultura irrigada da margem do São Francisco, em Petrolina.

Em Lucas do Rio Verde, em Mato Grosso, foi realizada uma pesquisa em anfíbios por exposição ambiental aos agrotóxicos. Analisaram o plasma sanguíneo de 14 sapos-cururu e 22 rãs-pimenta em dois córregos no município. Resíduos de endosulfan foram detectados em 7 sapos e em 11 rãs. Também foram detectados 5 indivíduos com má-formação (MOREIRA et al., 2010).

Como diz Larissa Bombardi, os agrotóxicos constituem hoje "uma arma silenciosa contra os direitos humanos" (BOMBARDI, 2011, p.1). No entanto, é importante destacar o uso dos agrotóxicos como "arma química" nos conflitos no campo brasileiro. A tensão sobre os territórios, principalmente das populações tradicionais e da agricultura familiar é constante.

A pulverização aérea é utilizada, também, para intimidação direta daqueles grupos que não querem produzir o modo do agronegócio. São verdadeiras "nuvens de veneno" que se dispersam no ar e atingem plantações vizinhas, cidades e a biodiversidade do entorno. Na luta pelos seus tekohas, no Mato Grosso do Sul, os Guarani e Kaiowá presenciam ataques constantes nas áreas onde habitam, além da degradação que existe nas áreas a serem reconquistadas.

Trago aqui o relato de um homem indígena, que descreve a intoxicação que o atingiu no ano de 2017.

Foi de manhã cedo, por volta das 8 da manhã; o trator estava pulverizando e senti o cheiro [do agrotóxico]. Dava pra ver o líquido branco [no ar]. Mesmo cheirando, vai para o seu cérebro. Você sente uma amargura na garganta. Você não quer mais respirar veneno - você quer respirar outro tipo de ar - mas não tem nenhum. Então você se sente fraco - você não consegue se levantar, porque o veneno é muito forte e fica com febre e dor de cabeça.... Você coloca a mão na sua cabeça e sente ela 


\begin{abstract}
latejando. Eu tive essa dor de cabeça muitas vezes, não aguento mais. Naquele dia, eu tive diarreia e vômito. Todo mundo que vive na beira da nossa comunidade passou mal. Enquanto eu esperava a ambulância, eu fiquei deitado na cama, me sentindo fraco. No hospital expliquei o que eu tinha e a causa. Eles me deram soro e um remédio e eu recebi alta no dia seguinte. Quando eu recebi alta do hospital, o médico me disse para me proteger, mas não tem jeito (HUMAN RIGTH WATCH, 2017, p.46).
\end{abstract}

Segundo a Audiência Pública realizada na Assembleia Legislativa de Mato Grosso do Sul, em novembro de 2016, a cana-de-açúcar é o cultivo que mais utiliza agrotóxicos em pulverização aérea, sendo que apenas $32 \%$ é depositado nas plantas, os demais vão parar no solo (49\%), ou são dispersados pelo vento (19\%), chegando a alcançar uma distância de até 32 quilômetros ${ }^{14}$.

A cana, assim como a soja, concentra-se em grande parte nas terras de maior conflito entre os indígenas e os fazendeiros. Dentre os 10 municípios maiores produtores de cana no estado, sete estão na zona de conflito: Rio Brilhante, Nova Alvorada do Sul, Ponta Porã, Ivinhema, Dourados e Maracaju, estando aí a maior concentração de usinas do estado (Monteiro, 2017).

O Dossiê Abrasco corrobora que a contaminação por agrotóxicos é decorrente da estratégia para expropriação de terras pelo agronegócio. Nele citam o caso da Comunidade do Km 69, em Limoeiro do Norte do Ceará,

\begin{abstract}
essa comunidade quase foi destruída em decorrência do cruel artifício adotado pelas empresas de espalhar enxofre na direção das comunidades. Como corolário, grande parte das famílias foi obrigada a vender suas terras por um preço irrisório ao agronegócio, ou mesmo a abandoná-las, devido aos frequentes problemas de saúde ocasionados pelo contato com essa substância tóxica (MARINHO, 2010). (ABRASCO, p.154, 2015)
\end{abstract}

Outro exemplo representativo é o de Dona Valdiva, moradora de Confresa, no Vale do Araguaia, em Mato Grosso ${ }^{15}$. Seu caso é emblemático por resistir a fortes pressões do agronegócio, desde a ameaças de morte, até mesmo a agressões físicas. No entanto, os ataques com o veneno já a fizeram sair uma vez de sua terra, podendo vir a se repetir novamente agora. A comunidade em que ela vivia tinha 80 famílias, porém uma a uma foi deixando o local, por pressão do processo de grilagem de terras que ali existe. Sua renda era baseada nos pés de pequi e de laranja, mas sua produção foi prejudicada, assim como seus animais que começaram a morrer.

"Só não resisti ao veneno. Eu fiquei com a terrinha de 36 alqueires, no meio de uma área de 16 mil hectares de lavoura de cana. Era avião o dia inteiro, jogando inseticida, herbicida. Eles usavam de estratégia, minha área virou ponto de manobra do avião, ele fazia o retorno em cima da minha terra. O vento puxava o veneno e vinha uma chuva em cima de nós" (CÍCERO; DOLCE, 2019, online). 
Depois de assentada em outra gleba, no mesmo município, Dona Valdiva ainda sofre com a deriva do veneno que é lançado nas fazendas, agora de soja, do seu entorno. E em seu relato ela demonstra como funciona o movimento de espoliação de terras na fronteira.

\footnotetext{
"E sei também que daqui a dez anos esses assentamentos onde estamos, onde tiver terra plana que dá para virar soja, vai virar. Não sei como vamos viver. Aqui já sentimos os efeitos, não sei se é da [fazenda] Luta, se é da fazenda que fica aqui atrás. Mas a mandioca, embola o olho todinho, fica empedradinho. As plantas murcham, quebram, endurecem e não voltam mais" (CÍCERO; DOLCE, 2019, online).
}

Esses são alguns dos exemplos dos muitos que acontecem no Brasil. O agrotóxico para além do aumento da produtividade, tornou-se instrumento de espoliação. O sistema do agronegócio não admite o diferente, não permite a convivência do outro. A monocultura predomina não somente nas terras por onde eles passam, mas nas mentes, como nos diz Vandana Shiva. Espaços que não se adequam ao capitalismo monocultor do agronegócio são tidos como espaços não produtivos, por mais que os pés de pequi, da Dona Valdiva, dessem frutos e sustento econômico para aquela família.

Vandana Shiva nos diz que as monoculturas exterminam a vida, a auto-organização da vida, a sustentabilidade das comunidades locais, para transformar tudo em propriedade de um único sistema. Assim, observamos que o modo de produção do agronegócio tem práticas fascistas, por não reconhecer o outro e pela necessidade de exterminá-lo.

O governo atual intensifica e colabora para as práticas destruidoras da diversidade no país, seja no campo ou em outras instâncias. A liberação de agrotóxicos está ocorrendo num ritmo cada vez mais acelerado ${ }^{16}$. No primeiro ano do governo Bolsonaro, 2019, foram liberados 474 tipos diferente de agrotóxicos no país, em 2020, em plena pandemia, foram liberados mais 493 tipos, e até final de setembro de 2021 mais 411. Totalizando 1.378 agrotóxicos liberados desde o início do mandato Bolsonaro ${ }^{17}$.

\section{Alertas da boiada passando}

Pontuaremos apenas quatro exemplos de projetos que tramitam na esfera federal, que ameaçam os direitos ambientais já constituídos:

a) PL 2633/2020 18

É o Projeto de Lei da grilagem de terra, criada com a justificativa de combatê-la. No entanto, abre mais brechas para sua legalidade. Permite, por exemplo, titular áreas desmatadas ilegalmente, pois não se exigirá regularização de passivo ambiental. Possibilita que a pessoa, que recebeu o título do imóvel, pratique desmatamento de forma ilegal em até dez anos.

b) PL $490 / 2007^{19}$ 
Coloca todas as Terras Indígenas, até então demarcadas, em uma situação de insegurança jurídica. Impõe a Tese do Marco Temporal, sendo este a justificativa utilizada pela Bancada Ruralista, assim como dos advogados dos fazendeiros, ao alegar que a Constituição garante as terras somente habitadas pelos indígenas no dia 5 de outubro de 1988 , desconsiderando as violações que ocorreram sobre os povos indígenas em períodos que antecederam este marco.

Constitui-se como uma barreira para aqueles que foram expulsos de suas terras antes desta data. Os aspectos referentes à demarcação das terras, correspondem ao modo tradicional indígena de utilização e produção das mesmas, de acordo com a especificidade dos costumes de cada comunidade. Ao considerar como aspecto principal a temporalidade marcada pela data da Constituição, há a violação dos precedentes de tradicionalidade e ancestralidade dos povos.

\begin{abstract}
Ao exigir a sua comprovação, como prova da tentativa de regresso e interesse por parte da comunidade indígena em ocupar a terra tradicional, o judiciário brasileiro desqualifica e desconsidera uma série de fatos históricos importantes desde o processo de colonização. Desconsidera também, questões básicas que envolvem as diferenças culturais, como a língua, costumes e formas de organização daquelas comunidades. A própria tutela por parte de entes do poder estatal serviu como barreira para que os indígenas pudessem reivindicar seus direitos. Situação comprovadamente agravada no período ditatorial (1964-1985), [...] foram anos de terror, com políticas voltadas para o extermínio das comunidades indígenas, orquestradas inclusive pelo Serviço de Proteção ao Índio (SPI) (CUPSINKI, et all, 2017, online).
\end{abstract}

O marco temporal estabelece uma ruptura não somente no tempo, mas também no território, rompendo com a história e os precedentes que constituíram a área a ser demarcada. Tal justificativa apaga os processos de construção, de despossessão e de originalidade do território nacional, ameaçando diretamente os direitos dos povos indígenas que, ao longo da história, foram destituídos de suas terras (MONTEIRO, 2017).

c) PDL 177/2021 (Projeto de Decreto Legislativo) ${ }^{20}$

Que autoriza o presidente da república ir contra a convenção 169 da OIT (Organização Internacional do Trabalho), com a justificativa de desburocratizar os tramites que se pautam a essa convenção. Esta norma reconhece as aspirações dos povos indígenas a assumir o controle de suas próprias instituições e formas de vida, de seu desenvolvimento econômico, de manter e fortalecer suas identidades, línguas e religiões, dentro do âmbito dos estados onde moram.

d) PL 3729/2004 ${ }^{21}$

Segundo a videoconferência da Associação Brasileira de Antropologia ${ }^{22}$, a nova Lei Geral do Licenciamento Ambiental é a mãe de todas as boiadas. Ela marginaliza as 
perspectivas politizadoras do licenciamento ambiental, tirando de debate os movimentos sociais e as pessoas atingidas; esvazia a função pública da regulação ambiental e isenta a atividade empresarial da supervisão estatal e do controle social. Dentro dessa proposta, o Estado passaria a não ser mais regulador, tornando-se um entrave dos investimentos privados. Permite a junção de EIA/RIMAs (Estudo de Impactos Ambientais/Relatório de Impactos Ambientais) quando os empreendimentos forem na mesma área, além de permitir o reaproveitamento de EIA/RIMAs anteriores.

Propõe que 13 atividades tenham dispensa de licenciamento, incluídas todas atividades de agricultura, de pecuária extensiva e de silvicultura. Além disso, a licença será autodeclaratória, sem avaliação prévia para os pequenos e médios empreendimentos ${ }^{23}$.

A FUNAI só poderá se manifestar se for Terra Indígena homologada, excluindo-se, assim, 41\% das Terras Indígenas do Brasil. O mesmo ocorre com os quilombos, onde apenas os titulados serão considerados existentes. Além disso, nas Terras Indígenas, Quilombos e Unidades de Conservação, somente serão considerados os impactos avaliados como diretos ou dentro dessas áreas.

\section{CONSIDERAÇÕES FINAIS: POR UMA VISÃO ANTI-COLONIAL}

Em primeiro lugar, gostaríamos de trazer o questionamento sobre os modos unos do pensar, sobre as "monoculturas da mente". Precisamos questionar a construção do que concebemos como "universalidade". Aquilo que consideramos como "universal" parte sempre de uma perspectiva eurocêntrica. A priori é colocado "como se o conhecimento nascido na Europa que se reivindica de origem greco-romana fosse universal e, assim, fosse um conhecimento atópico, de lugar nenhum, e não um conhecimento também nascido em uma província específica do mundo, no caso, a Europa Ocidental" (MALHEIROS, PORTO-GONÇALVES \& MICHELOTTI, p.215, 2021).

O pensamento para além do greco-romano também pode/deve ser universalizado. Os modos de viver, de pensar, de produzir não são unos. É necessário dialogar com ontologias políticas diversas. O modo "universal" da racionalidade se materializa no território brasileiro, no assunto que tratamos aqui, pela lógica da expansão. Porém, como brasileiros, necessitamos construir projetos de país que dialoguem com os nossos saberes. Um projeto de país que não seja somente pautado pelo saber da expansão das commodities. No término da obra de "Horizontes Amazônicos", Malheiros, Porto-Gonçalves e Michelotti, os autores, versam sobre as necessidades de se pensar o Brasil valorizando a diversidade do país, principalmente, considerando a experiência dos povos amazônidas. Desse modo, eles apontam:

Por mais de 500 anos, histórias locais eeuurocentradas universalizaram um saber/poder da dominação/destruição que forjaram nossas escolhas políticas e projetos de des-envolvimento. Já passou da hora de considerarmos que o léxico teórico e político advindo da luta dos amazônidas carrega saberes/fazeres 


\begin{abstract}
comprometidos com a vida, prenhes de horizontes emancipatórios ao capitalismo e à colonialidade; o que nos exige colocar no centro de qualquer perspectiva de futuro, para todos nós, as perspectivas de futuro dos povos amazônicos. Afinal, se hoje a humanidade inteira se vê na Amazônia é preciso honrar a dignidade de seus povos que tornam todo esse debate possível. E não deixemos margem a dúvidas: Já Basta! Vida longa à Amazônia e seus povos! (MALHEIROS, PORTO-GONÇALVES \& MICHELOTTI, p.278, 2021).
\end{abstract}

Nesse contexto observamos que a expansão da fronteira para o plantio de commodities deixa um rastro de destruição e prejuízos socioambientais para o país. A lógica do agronegócio não permite o diverso. É uma lógica destrutiva! O discurso de que o agronegócio brasileiro tem a "missão de alimentar o mundo" não é verdadeiro. A missão é gerar lucro para eles e, assim, passar por cima de quem estiver pela frente - floresta, cerrado, indígenas, quilombolas, ambientalistas, padres, freiras, crianças, lactantes, etc.

O discurso deles de "alimentar o mundo", não passa por uma perspectiva de soberania alimentar. O projeto de país construído pelo agronegócio é em benefício de poucos, voltado especificamente para a exportação de produtos, quase sempre, in natura, para o exterior. $\mathrm{O}$ projeto econômico, pautado na expansão da produção de commodities, que avança na fronteira com a floresta na Amazônia ou no Matopiba, também avança nos nossos pratos. A fronteira agrícola no modelo do agronegócio reverbera na nossa mesa. Os cultivos de soja, milho, cana, algodão crescem a cada ano, em contrapartida, o arroz, o feijão e a mandioca perdem espaço em área plantada (ALENTEJANO, 2021). A lógica é inversamente proporcional.

De acordo com a Rede Brasileira de Pesquisa em Soberania e Segurança Alimentar e Nutricional (Rede Penssan), no final de 2020, cerca de 19 milhões de brasileiros passaram fome, sendo que 55,2\% dos domicílios no país enfrentaram algum grau de insegurança alimentar, aproximadamente 116,8 milhões de pessoas.

Esse não é um problema de agora na pandemia. Dados de 2018, do Ministério da Cidadania, ao mapear a insegurança alimentar e nutricional no Brasil, revelaram que em 2017 morreram 15 pessoas por dia de fome, inclusive em Mato Grosso, o "celeiro do agro que alimenta o mundo". A pergunta que fazemos é: se o agronegócio brasileiro alimenta o mundo, porque tem brasileiro morrendo de fome?

Os preços atuais do arroz, do feijão, do óleo de soja, da carne, do frango, revelam o projeto político alimentar desse setor. O "agro pop" que alimenta o mundo, coloca o litro de óleo de soja a quase 9 reais nas gôndolas dos supermercados. A missão do agronegócio nunca foi alimentar o mundo. Portanto, como diz Milton Santos em "Por uma outra globalização", eles pintam este mundo globalizado como fábula, e nós aqui denunciamos como ele verdadeiramente é para a grande maior parte da humanidade, uma globalização que se impõe como uma "fábrica de perversidade" (p.19, 2000).

A pujança do setor vem desde antes do governo atual. Governos progressistas no Brasil e na América Latina permitiram, também, a perpetuação e a aceleração desse sistema. 
Por isso a necessidade de dialogarmos um projeto político de país que pense criticamente os modos de produção do meio agroexportador. No entanto, no governo atual o agronegócio encontrou terreno mais fértil do que nunca para se expandir. Não aponto somente para a articulação do executivo com a bancada ruralista, mas, principalmente, no fortalecimento de uma psicosfera que passa a ser cada vez mais legitimada. O agronegócio não é somente o modo de produzir, o agronegócio está no modo de pensar.

O modo de produzir do agronegócio não permite a convivência do diverso. Não permite a existência dos pés de pequi da Dona Valdiva, não permite que os Guarani-Kaiowá sobrevivam em seus tekohas, não permite a proteção da floresta pela Dorothy Stang, não permite que a Amazônia permaneça em pé, não permite que as mães de Lucas do Rio Verde possam amamentar sem veneno seus filhos, não permite que a Professora Larissa Bombardi faça sua pesquisa na USP, não permite que a população de Correntina na Bahia tenha o direito básico do acesso à água, não permite sequer a existência plena de um sapo-cururu nos córregos que cruzam a BR-163 mato-grossense. Dessa forma, é um sistema produtivo que extingue, espolia, persegue e mata seus diferentes. Não é coincidência o pacto político desse setor com o governo Bolsonaro.

A crítica ao agronegócio faz com que nos conectemos com as lutas populares, valorizando, também, a cultura popular que resiste com muita força e não se deixa intimidar pela força da indústria cultural do agronegócio. Dessa forma, necessitamos, como país, e principalmente como geógrafos, reconhecer e escutar os territórios. Na emergência atual, que a geografia dê ouvidos aos territórios.

Portanto, necessitamos nos conectar com os territórios e com as territorialidades, mantendo sempre a humildade de aprender e de pensar um Brasil que, minimamente, permita a existência do diverso. Nesse sentido, trago a reflexão e a importância, para a Geografia, de pensarmos um território a partir de uma América Latina, da Abya Yala/ Afro/ Latino América (ESCOBAR, 2016), uma noção territorial para além dos conceitos e práticas hegemônicas,

\footnotetext{
que brota da base, dos cotidianos vividos no calor das r-existências (como nos mostra Zibechi, 2015) que, se não estão tão disseminadas, atuam como um fermento na construção de outras formas de sentir, de falar e de fazer (multi)territorialidades -sempre no plural, em consonância com o pluriverso preconizado pela descolonialidade (HASBAERT, p. 71, 2021).
}

Dessa forma, é importante conceber que a Amazônia e o Cerrado não são somente biomas, são também culturas. A fronteira agrícola capitalista, quando chega, produz apagamentos, desmata a floresta, mas também tenta desmatar as memórias. Assim, Ayala Ferreira (2021), liderança do MST, afirma que a existência dos amazônidas gera conflito com o capitalismo, já que o avanço do capitalismo aniquila o outro, como é o caso do agronegócio sobre os territórios. O modo de reprodução do agronegócio perpassa por processos de extermínio; podemos dizer que não há possibilidade de convivência quando um modus 
operandi ameaça a existência dos demais. Como coexistir pacificamente quando o outro opera para te extinguir?

Destaco a ideia do último capítulo do livro "Por uma outra globalização", do Milton Santos, onde ele nos afirma, em seu título, que "a globalização não é irreversível". Assim, pensamos que podemos construir um projeto de país que afirme as pluralidades existentes de seu território e que o conecte com os projetos políticos plurinacionais dos países vizinhos da Abya Yala/ Afro/Latino América. Como acadêmicos, temos que compreender que as

realizações atuais, oriundas de ações hegemônicas, têm como base construções intelectuais fabricadas antes mesmo da fabricação das coisas e das decisões de agir. A intelectualização da vida social, recentemente alcançada, vem acompanhada de uma forte ideologização (SANTOS, p. 159, 2000).

Necessitamos superar "os projetos mononacionais de uma nação que encarnou o ecocídio, o patriarcado, o racismo, o patrimonialismo e a violação étnica como regra de des-envolvimento" e dentro e fora da academia precisamos questionar as bases do pensamento, buscando não reproduzir "internamente a colonialidade" de um eeuurocentrismo que colonizou o mundo (MALHEIROS, PORTO-GONÇALVES \& MICHELOTTI, p.19, 2021).

Concluímos, trazendo um exemplo de uma possibilidade de produzir alimento, respeitando o território e os saberes. O Projeto RECA (Reflorestamento Econômico Consorciado e Adensado), citado no livro "Horizontes Amazônicos", é um exemplo de um assentamento no município de Porto Velho, Rondônia. Um grupo de assentados, oriundos em sua maioria do sul do país, "abandonados à sua própria sorte, os assentados, (...) mal-acostumados a derrubar a floresta e, com a terra nua, f(i)zerem suas plantações, viram o solo desnudo logo perder a fertilidade pelas chuvas intensas" (MALHEIROS, PORTO-GONÇALVES \& MICHELOTTI, p.236, 2021).

Sem ajuda e acompanhamento do Estado (estaduais - Rondônia e Acre - e federal), o grupo desenvolveu alternativas próprias. Destaca-se, que a mais importante,

foi perder a visão colonial que costuma acompanhar os migrantes do sul quando chegam na Amazônia (ou no Nordeste). Esses assentados puderam se beneficiar dos métodos de educação popular inspirados em Paulo Freire, que vicejavam entre os que lutavam pela terra e foram buscar informações junto aos caboclos, os camponeses etnicamente diferenciados que ali viviam (ibdem).

Assim, com os saberes da população cabocla/indígena descobriram que era possível plantar em meio à floresta. São mais de 40 anos de produção de alimentos no sistema agroflorestal, compartilhando saberes com os povos amazônidas, produzindo 
secas e fermentadas (MALHEIROS, PORTO-GONÇALVES \& MICHELOTTI, p.237, 2021).

Dessa forma, podemos ver uma situação onde o acesso à terra e a dignidade dos povos foram mantidos em comunhão com a floresta em pé. A busca por respeito e reprodução dos saberes milenares que existem nos povos indígenas da Amazônia, revela-se reinventada no intercâmbio cultural, em um território de convivência respeitosa entre os povos.

\section{NOTAS}

1 - Região geoeconômica delimitada pela EMBRAPA (Empresa Brasileira de Pesquisa Agropecuária) com interesses em desenvolver em área produtoras com potencial agrícola para a expansão do cultivo de grãos a totalidade do estado do Tocantins e a parcialidade dos estados do Maranhão, Piauí e Bahia.

2- Destaca-se as formas de milícias legitimadas informalmente pelo atual governo brasileiro (MALHEIRO, 2021).

3 - Até o momento não existia nenhum órgão que atuasse especificamente com a questão ambiental no Brasil. Com a Conferência de Estocolmo em 1972, houve a necessidade de o Brasil mandar representantes. Com isso foi criada, a partir de então, a Secretaria Especial de Meio Ambiente.

4 - E se propaga até o momento final da escrita deste artigo.

5 - Para mais informações ver os artigos do Caderno Especial "Crise e Populismo" do Le Monde Diplomatique Brasil, escrito pelo Grupo de Pesquisa Discurso:

- "Jair Bolsonaro: tudo agora é pandemia, tem que acabar com esse negócio". Disponível em: https://diplomatique.org.br/jair-bolsonaro-tudo-agora-e-pandemia-tem-que-acabar-com-esse-negocio/

Acessado em 27 out. 21.

- "As mídias, a reprodução dos discursos negacionista e científico e a reconfiguração política em curso". Disponível em:

https://diplomatique.org.br/as-midias-a-reproducao-dos-discursos-negacionista-e-cientifico-e-a-reconfiguracao -politica-em-curso/. Acessado em 27 out. 21.

- ““Uma gripezinha”: A análise política do discurso negacionista”. Disponível em:

https://diplomatique.org.br/uma-gripezinha-a-analise-politica-do-discurso-negacionista/ . Acessado em 27 out. 21.

6 - Altamira (PA), São Félix do Xingu (PA), Porto Velho (RO), Lábrea (AM), Balsas (MA), Novo Progresso (PA), Itaituba (PA), Apuí (AM), Pacajá (PA), Portel (PA).

7- O primeiro passo a se grilar uma terra é desmata-la, em seguida é registrá-la no CAR. Ver próximo item: "A fronteira agrícola no rastro da grilagem".

8 - Destaca-se que os dados não contabilizam as áreas indígenas ainda não demarcadas.

9 - Frase título do livro "Dono é quem desmata: conexões entre grilagem e desmatamento no sudoeste paraense" (TORRES, DOBLAS \&ALARCON, 2017)

10 - SANTOS, 1996 e RIBEIRO, 1991 
https:/g1.globo.com/fantastico/noticia/2020/04/19/audios-e-videos-revelam-detalhes-de-esquema-de-grilagem-d entro-de-terras-indigenas.ghtml

12 - A pesquisa foi realizada em todos os estados brasileiros.

13 - Ver "quadro 1.2 Classificação e efeitos e/ou sintomas agudos e crônicos dos agrotóxicos" da página 59 do "Dossiê ABRASCO: um alerta sobre os impactos dos agrotóxicos na saúde". Disponível em: https://www.abrasco.org.br/dossieagrotoxicos/wp-content/uploads/2013/10/DossieAbrasco_2015_web.pdf

14 - Audiência debate alternativas para aperfeiçoar legislação da pulverização no Estado. Disponível em: http://www.al.ms.gov.br/Default.aspx?tabid=56\&ltemld=48338 Acessado em: 30 jun. 2017.

15 - Depoimento registrado na reportagem da A Pública "Ameaçados pelo veneno". Disponível em: https://apublica.org/video/2019/08/ameacados-pelo-veneno/

16 - Diversos agrotóxicos que são proibidos em várias partes do mundo, devido ao forte risco de contaminação foram liberados no Brasil durante a gestão do governo Bolsonaro.

17 - Fonte: Ministério da Agricultura e G1. Disponível em: https://g1.globo.com/economia/agronegocios/noticia/2021/09/29/ministerio-da-agricultura-registra-2-agrotoxi cos-ineditos-e-mais-51-genericos-para-uso-dos-agricultores.ghtml

18 - Ver em: https://www.camara.leg.br/proposicoesWeb/fichadetramitacao?idProposicao=2252589

19 - Ver em: https://www.camara.leg.br/propostas-legislativas/345311

20 - Ver em: https://www.camara.leg.br/propostas-legislativas/2279486

\section{1 - Ver em: https://www.camara.leg.br/proposicoesWeb/fichadetramitacao?idProposicao=257161}

22 - Ver em: "A nova Lei Geral do Licenciamento Ambiental. A mãe de todas as boiadas (Semana de Meio Ambiente da ABA". Disponível em: https://www.youtube.com/watch?v=SUVzOb5Rqdc Acessado em 20 ago. 2021.

23 - Destaca-se que em alguns empreendimentos médios há a remoção de pessoa. Dessa maneira, a remoção de grupos de seus locais seria estabelecida apenas por uma licença autodeclaratória do próprio empreendedor.

\section{REFERÊNCIAS}

ABRASCO. Dossiê. ABRASCO: um alerta sobre os impactos dos agrotóxicos na saúde. Orgs. CARNEIRO, Fernando Ferreira; et all. Rio de Janeiro: EPSJV; São Paulo: Expressão Popular, 2015

AGUIAR, Diana; TORRES, Mauricio. A boiada está passando: desmatar para grilar. In: Dossiê Agro é fogo, 2020. Disponível em: https://agroefogo.org.br/a-boiada-esta-passando-desmatar-para-grilar/. Acessado em: 18 jun. 2020.

ALENTEJANO, Paulo Roberto Raposo. O avanço do agronegócio no Brasil: gestão produtiva ou produção da miséria? In: Mesa 16 do XIV Encontro Nacional de Pós-Graduação em Geografia. João Pessoa, 13 out. 2021. Disponível em: https://www.youtube.com/watch?v=toLK1_3WDpc Acessado em: 13 out. 2021.

AUGUSTO, LGS, et al. Impactos dos agrotóxicos sobre a saúde e o meio ambiente. Revista PUC Vida, São Paulo, 1 dez. 2010

BERNARDES, Júlia Adão. A expansão do agronegócio no cerrado e na Amazônia Legal na contemporaneidade: discussão do conceito fronteira. Curso Geografia e Agronegócio - PPGG/UFRJ. Notas de Aula, 14 set. 2021. 
BERNARDES, Júlia Adão. Aula 05: A expansão do agronegócio no cerrado e na Amazônia Legal na contemporaneidade: discussão do conceito fronteira. In: Curso Geografia e Agronegócio. Programa de Pós=Graduação em Geografia. Univeridade Federal do Rio de Janeiro, 2021.

BERNARDES, Júlia Adão; SANTOS, Patrícia Cristina Rosa; NASCIMENTO, Ayrton Senna Silva do. Repercussões socioambientais do consumo de agrotóxicos: a produção de grãos na BR-163 mato-grossense. In: BERNARDES, Júlia Adão et all. (Orgs.). O setor carne-grãos no Centro-Oeste: circuitos produtivos, dinâmicas territoriais e contradições. Rio de Janeiro: Lamparina, 2021

BRANDÃO, Carlos. Acumulação primitiva permanente e desenvolvimento capitalista no Brasil contemporâneo. In: ALMEIDA, Alfredo Wagner Berno de. et al. Capitalismo globalizado e recursos territoriais: fronteiras da acumulação no Brasil contemporâneo. Rio de Janeiro: Lamparina, 2010.

BOMBARDI, Larissa. A intoxicação por agrotóxicos no Brasil e a violação dos direitos humanos. Direitos humanos no Brasil 2011: Relatório da Rede Social de Justiça e Direitos Humanos. São Paulo: Expressão Popular, 2011.

CÍCERO, José; DOLCE, Júlia. Ameaçados pelo veneno. In: A pública. 19 ago. 2019. Disponível: https://apublica.org/video/2019/08/ameacados-pelo-veneno/ Acessado em: 04 mai. 2021

CUPSINKI, Adelar; PEREIRA, Alessandra Farias Pereira; SANTOS, Rafael Modesto; GUEDES, Íris Pereira; LIEBGOTT, Roberto Antônio. Terra tradicionalmente ocupada, Direito originário e a inconstitucionalidade do Marco Temporal ante a proeminência dos art. 231 e 232 da Constituição. In: Combate ao Racismo Ambiental. Disponível em: http://racismoambiental.net.br/2017/01/26/terra-tradicionalmente-ocupada-direito-originario-e-a-inconstitucionalidade-d o-marco-temporal-ante-a-proeminencia-do-art-231-e-232-da-constituicao/ Acessado em: 8 jun. 2021.

DORES, EFGC; CALHEIROS, DF. Contaminação por agrotóxicos na bacia do rio Miranda, Pantanal (MS). Revista Brasileira de Agroecologia, vol. 3, supl. 202 esp., 2008

ESCOBAR, A. Desde abajo, por la izquierda y con la Tierra: La diferencia de Abya Yala/Afro/Latino-América. In: Gudynas, E. et al. Rescatar la esperanza: más allá del neoliberalismo y el progresismo. Barcelona: Entre Pueblos, 2016.

FERREIRA, Ayala. Horizontes amazônicos: para repensar o Brasil e o mundo. In: Curso Emergências, módulo 1/aula 3. Expressão Popular. 15 jun. 2021 Disponível em: https://www.youtube.com/watch?v=DgZjmjgFhTM Acessado em: 15 jun. 2021.

FONSECA, Alberto de Freitas Castro; PRADO FILHO, José Francisco do. Um Importante Episódio na História da Gestão dos Recursos Hídricos no Brasil: O Controle da Coroa Portuguesa Sobre o Uso da Água nas Minas de Ouro Coloniais. RBRH - Revista Brasileira de Recursos Hídricos. v. 11. n.3 Jul/Set, 2006, p. 5-14.

HARVEY, David. O Novo Imperialismo. Edições Loyola, 2005

MALHEIRO, Bruno. Pensar a Amazônia para entender o Brasil: dos desmontes aos horizontes. In: Mesa 02 Política Ambiental: Desmonte e resistência no Campo Brasileiro. Palestra/live. Belém: Encontro Nacional de Geografia Agrária, 2021. Disponível em : https://www.youtube.com/watch?v=0fSvkvu41kw Acessado em: 08 abr. 2021

MALHEIRO, Bruno; PORTO-GONÇALVES, Carlos Walter; MICHELOTTI, Fernando. Horizontes amazônicos: para repensar o Brasil e o mundo. São Paulo: Fundação Rosa Luxemburgo; Expressão Popular, 2021.

MAPBIOMAS. Relatório Anual do Desmatamento no Brasil 2020. São Paulo: MapBiomas, 2021.

MIRANDA, KA et al. Pesticide residues in river sediments from the Pantanal Wetland, Brazil. Journal of Environmental Science and Health.vol. 43, p. 717-574, 2008.

MONTEIRO, Daniel Macedo Lopes Vasques. Disputa territorial no Mato Grosso do Sul: o tempo do direito dos Guarani-Kaiowá e Guarani-Ñandéva e as estratégias e táticas do agronegócio. Rio de Janeiro, 2017. Dissertação de mestrado (Mestrado em Geografia), Instituto de Geociências, Universidade Federal do Rio de Janeiro.

MOREIRA, JC et al. Avaliação do risco à saúde humana decorrente do uso de agrotóxicos na agricultura e pecuária na região Centro-Oeste. Relatório de Pesquisa. Brasília: CNPq 555193/2006-3, 2010. 
HAESBAERT, Rogério. Território e descolonialidade: sobre o giro (multi) territorial/de(s)colonial na América Latina. Ciudad Autónoma de Buenos Aires: CLACSO; Niterói: Programa de Pós-Graduação em Geografía; Universidade Federal Fluminense, 2021.

HUMAN RIGTH WATCH, Relatório. "Você não quer mais respirar veneno" As falhas do Brasil na proteção de comunidades rurais expostas à dispersão de agrotóxicos. In: Human Rigth Watch, 2017. Disponível em https://www.hrw.org/pt/report/2018/07/20/320394\#_ftn37 Acessado em 20 jun. 2020

REDE PENSSAN. Rede Brasileira de Pesquisa em Soberania e Segurança Alimentar e Nutricional. Relatório Insegurança Alimentar e Covid-19 no Brasil. Disponível em: http://olheparaafome.com.br/VIGISAN_Inseguranca_alimentar.pdf Acessado em 10 out. 2020.

RIBEIRO, Ana Clara Torres. Matéria e espírito: o poder (des)organizador dos meios de comunicação. In: PIQUET, R; RIBEIRO, A. C. T. Brasil, território da desigualdade. Rio de Janeiro: Jorge Zahar editora, 1991.

SANTOS, Milton. A natureza do espaço. São Paulo: Hucitec, 1996.

SANTOS, Milton. Por uma outra globalização: do pensamento único à consciência universal. Editora Record: Rio de Janeiro, 2000.

SILVA, DR et al. Monitoramento de agrotóxicos em águas superficiais de regiões orizícolas no sul do Brasil. Ciência Rural [on-line], vol. 39, n. 9, p. 2.383-9, 2009.

SOARES, AFS et al. Estimativa de risco de contaminação de mananciais por agrotóxicos utilizados em culturas de café. Revista Brasileira de Engenharia Agrícola e Ambiental, vol.16, n. 4, p. 425-32, 2012.

SVAMPA, Maristela. As fronteiras do neoextrativismo na América Latina: conflitos socioambientais, giro ecoterritorial e novas dependências. São Paulo: Elefante, 2019.

TORRES, Mauricio; DOBLAS, Juan; ALARCON, Daniela Fernandes. Dono é quem desmata: conexões entre grilagem e desmatamento no sudoeste paraense. São Paulo: Urutu-branco; Altamira: Instituto Agronômico da Amazônia, 2017

\section{COMO CITAR ESTE TRABALHO}

MONTEIRO, Daniel Macedo Lopes Vasques. Processos de espoliações no Brasil atual: ofensivas do agronegócio sobre os direitos ambientais e territoriais. Revista Tamoios, São Gonçalo, v. 18, n. 1, p. 74-95, 2022. Disponível em: https://doi.org/10.12957/tamoios.2022.63317. Acesso em: DD MMM. AAAA. 